\title{
Cost-Effectiveness of a School-Based Social and Emotional Learning Intervention: Evidence from a Cluster-Randomised Controlled Trial of the Promoting Alternative Thinking Strategies Curriculum
}

\author{
Alex J. Turner $^{1}$ (D) $\cdot$ Matt Sutton ${ }^{1} \cdot$ Mark Harrison $^{2,3,4} \cdot$ Alexandra Hennessey $^{5} \cdot$ Neil Humphrey $^{5}$
}

Published online: 26 July 2019

(c) The Author(s) 2019

\begin{abstract}
Background School-based social and emotional learning interventions can improve wellbeing and educational attainment in childhood. However, there is no evidence on their effects on health-related quality of life (HRQoL) or on their cost effectiveness. Objective Our objective was to evaluate the cost effectiveness of the Promoting Alternative Thinking Strategies (PATHS) curriculum.

Methods A prospective economic evaluation was conducted alongside a cluster-randomised controlled trial of the PATHS curriculum implemented in the Greater Manchester area of England. In total, 23 schools ( $n=2676$ children) were randomised to receive PATHS, and 22 schools ( $n=2542$ children) were randomised to continue with usual practice. A UK health service perspective and a 2-year time horizon were used. HRQoL data were collected prospectively from all children in the trial via the Child Health Utility Nine-Dimension questionnaire. Micro-costing was undertaken to estimate the intervention costs. Missing data were imputed using multiple imputation.

Results The mean incremental cost of the PATHS curriculum compared with usual practice was $£ 32.01$ per child, and mean incremental quality-adjusted life-years (QALYs) were positive $(0.0019 ; 95 \%$ confidence interval [CI] 0.0009-0.0029). Assuming a willingness-to-pay threshold of $£ 20,000$ per QALY, the expected incremental net benefit of introducing the PATHS curriculum was $£ 5.56$ per child ( $95 \%$ CI -14.68 to 25.81 ), and the probability of cost effectiveness was $84 \%$. However, this probability fell to $0 \%$ when intervention costs included teacher's salary costs.

Conclusion The PATHS curriculum has the potential to be cost effective at standard UK willingness-to-pay thresholds. However, the sensitivity of the cost-effectiveness estimates to key assumptions means decision makers should seek further information before allocating scarce public resources.
\end{abstract}

Trial registration number ISRCTN85087674.

Electronic supplementary material The online version of this article (https://doi.org/10.1007/s40258-019-00498-z) contains supplementary material, which is available to authorized users.

Alex J. Turner

alexander.turner@manchester.ac.uk

Matt Sutton

matt.sutton@manchester.ac.uk

Mark Harrison

mark.harrison@ubc.ca

Alexandra Hennessey

alexandra.hennessey@manchester.ac.uk

Neil Humphrey

neil.humphrey@manchester.ac.uk

1 Centre for Primary Care and Health Services Research, The

University of Manchester, Suite 6 Williamson Building,

Oxford Road, Manchester M13 9QQ, UK
2 Faculty of Pharmaceutical Sciences, University of British Columbia, Vancouver, Canada

3 Centre for Health Evaluation and Outcome Sciences, St. Paul's Hospital, Vancouver, Canada

4 Manchester Centre for Health Economics, The University of Manchester, Manchester, UK

5 Manchester Institute of Education, The University of Manchester, Manchester, UK 


\section{Key Points for Decision Makers}

This cluster-randomised controlled trial suggested that the Promoting Alternative Thinking Strategies (PATHS) curriculum is associated with a small increase in both QALYs and costs.

School-based social and emotional learning interventions such as PATHS have the potential to be cost effective at conventional willingness-to-pay thresholds used in the UK.

The probability of cost effectiveness is sensitive to assumptions made regarding the costs included.

\section{Introduction}

The development of age-appropriate social and emotional skills such as empathy and self-regulation during infancy, childhood and adolescence represent important milestones [1]. They are associated with a range of important later-life outcomes, including mental health and wellbeing, health and health behaviours, family and relationship stability and labour market success [2]. Improving these skills is key for driving social progress [3], and national guidelines encourage their promotion in children [4-6].

Social and emotional learning (SEL) interventions have grown significantly in popularity in recent years [7]. These aim to improve social and emotional skills via explicit instruction in the context of safe, caring, well-managed and participatory learning environments. Four recent meta-analyses provided robust evidence that SEL interventions can enhance such skills, attitudes towards self and others, mental health, and academic attainment of children and young people [8-11]. A fifth demonstrated that these effects are sustained over time [12].

One SEL intervention, the Promoting Alternative Thinking Strategies (PATHS) curriculum, was recommended to the UK government as part of an influential report on early interventions in child development [13]. Developed in the USA, the aim of PATHS is to promote self-control, emotional understanding, positive self-esteem, relationships and interpersonal problem-solving skills among children in pre-school and primary education settings through the provision of a taught curriculum [14]. Numerous randomised controlled trials (RCTs) have consistently established small-to-moderate effects on a range of outcomes, including children's social and emotional skills, externalising problems (e.g. aggressive behaviour) and academic attainment [15-25]. However, many trials finding positive effects of
PATHS have involved or been led by the developer. The small number of independent trials conducted in the USA [18], Switzerland [22] and England [20] have largely yielded null results.

Furthermore, there is currently no published cost-utility analyses (CUAs) of PATHS [26]. A single study conducted a micro-costing of a pre-school PATHS intervention but did not compare costs with outcomes because no statistically significant effects on social and emotional wellbeing were found [20]. The only cost-effectiveness analysis (CEA) of an SEL intervention examined the value for money of a different intervention, the Social Skills Improvement System (SSIS) and also measured programme benefits using social skills only [27]. In the UK, national guidelines have repeatedly called for more information on the value for money of SEL interventions [5, 6]. CUA is required for PATHS to garner funding from the UK national health service (NHS). CUA also provides advantages over CEA in this context because benefits are measured using HRQoL, which allows the measurement of effects on domains of health other than social and emotional wellbeing and provides a cost-effectiveness threshold that can be used to benchmark value for money against that of alternative interventions.

This study collected primary data on HRQoL and PATHS intervention costs to conduct a trial-based economic evaluation following the National Institute for Health and Care Excellence (NICE) reference case [28]. It is the first study to conduct a CUA of a universal SEL intervention, and it does so using data from one of the few RCTs run independently of intervention developers.

\section{Methods}

\subsection{Trial Design}

Full details of the trial design and participants are reported elsewhere [29]. In brief, a two-arm cluster RCT design was utilised, with schools used as the unit of randomisation. Schools were randomly allocated on a 1:1 basis to implement PATHS or continue with their usual practice. Data were collected at baseline (May-July 2012) and at 12- and 24-month follow-ups. Adaptive stratification was employed to ensure that the trial arms were balanced on the proportions of children eligible for free school meals and speaking English as an additional language (EAL). Randomisation was performed independently by the Manchester Academic Health Science Centre Clinical Trials Unit. The study received ethical approval from the University of Manchester Research Ethics Committee (Ref: 11470). 


\subsection{Participants}

All mainstream, state-maintained institutions providing education for children aged 4-11 years in the ten local authorities in Greater Manchester were eligible for the study. School participation required consent from the head teacher. Participants within each school were children aged 7-9 years at baseline (year groups 3-5). Child participation required a lack of parental and child opt-out.

\subsection{Sample Size}

Initially, 58 schools were recruited, 45 of which met the eligibility criteria for randomisation. In total, 23 schools were randomised to receive PATHS; 140 parents (3\%) exercised their right to opt their children out of the trial. A total of 5218 children participated in the study ( $n=2676$ in the intervention arm).

Characteristics of participating schools mirrored those of primary schools in England in respect of attendance, attainment and proportion of pupils speaking EAL but were significantly larger, with higher proportions of pupils eligible for free school meals and lower proportions identified as having special education needs. Characterisics of participating pupils (aged 7-9 at baseline) aligned closely with those of English primary school-aged children [30, 31], although the prevalence of children eligible for free school meals and speaking EAL was higher [32-35].

\subsection{Intervention and Comparator}

\subsubsection{Intervention}

Each participating class received curriculum packs containing lessons (and some supplementary send-home activities) built around four conceptual units (emotional understanding, self-control, social problem-solving, peer relations and self-esteem), plus associated material resources (e.g. posters, feelings dictionaries) [36]. Teachers also received a guidance manual developed by the research team that emphasized the programme theory and importance of effective implementation.

PATHS was implemented and delivered by class teachers as part of the general classroom timetable for year groups $3-5$ in the first year of the trial (4-6 in the second year). All were qualified teachers and had an average of 8 years' teaching experience; $81 \%$ were female. PATHS lessons lasted 30-40 min and were designed to be delivered twice weekly throughout the school year. Curriculum packs contained an average of 40 lessons.

In the first year of the trial, teachers of year groups 3-5 in the treatment arm received a full day of initial group training prior to the school year, with a half-day follow-up 4 months later. This training was led by certified trainers from Pennsylvania State University (PSU). They were aided by three PATHS coaches from the research team, who received training on supporting PATHS implementation during a visit to PSU. Where teachers could not attend the group training sessions, one-on-one training was carried out by a PATHS coach. Where teachers left part-way through a school year, training for replacement teachers was also carried out on a one-on-one basis by a PATHS coach.

In the second year of the trial, teachers of year group 6 and newly starting year group 4-5 teachers also received the above training. PATHS coaches conducted all second-year training and provided teachers with ongoing technical support and assistance, including modelling of and feedback on lessons.

\subsubsection{Usual Practice}

School-level surveys ascertaining the level of engagement with non-PATHS SEL-related activities were completed by the member of staff with lead responsibility for personal, social and health education in both PATHS and control schools before and during the intervention period. Findings from these surveys, presented elsewhere [29], revealed that, both pre and post-implementation, schools in both the PATHS and the control arms engaged in a range of other SEL-related activities. The volumes of these activities were relatively balanced across arms pre-PATHS implementation. Post-PATHS implementation, most control schools were implementing the universal elements of the Social and Emotional Aspects of Learning (SEAL) programme [37] (82\% using the whole school resources, such as assemblies; $72 \%$ delivering SEAL lessons) and were delivering the National Healthy Schools Programme [38] (75\%) and Circle Time [39] (60\%). In total, 32\% of control schools were using nurture groups [40], 28\% were implementing the small group work component of SEAL, 25\% were involved in the Targeted Mental Health in Schools initiative [41] and 26\% were using restorative justice techniques [42]. All of these activities were conducted in classroom time and delivered by classroom teachers, and all aimed to improve children's emotional wellbeing. Although PATHS was designed to be implemented in addition to these other activities, a comparison of pre and post-implementation surveys suggested that PATHS did lead to some displacement of other SEL-related activities, with reductions primarily seen for elements of the SEAL programme [29].

\subsection{Perspective and Time Horizon}

A 2-year time horizon (consistent with the length of the trial) was used. Analysis was conducted from a UK health service perspective, assuming that the NHS would fund incremental 
costs of PATHS compared with costs incurred in usual practice (e.g. additional training requirements) but that schools would continue to be responsible for costs involved in the delivery of the curriculum (e.g. teachers' salary costs).

\subsection{Outcome Measure}

The Child Health Utility Nine-Dimension (CHU-9D) is a generic, multi-attribute, preference-based measure of HRQoL constructed specifically for use in children aged 7-11 years [43, 44]. It measures HRQoL based on nine attributes (worried, sad, pain, tired, annoyed, schoolwork/ homework, sleep, daily routine and activities), each scored on five levels. Preference weights derived using the standard gamble method in a sample of UK adults were used to transform responses to the CHU-9D to utility values ranging from 0.33 to 1 (perfect health), with a value of 0 equivalent to death [45].

Participants self-completed the CHU-9D questionnaire in a classroom setting at baseline and at the 12-month and 24-month follow-ups. CHU-9D utility values at each time point were used to calculate quality-adjusted life-years (QALYs) using the area under the curve method, assuming utilities followed a linear path over time [46]. QALYs were discounted at a rate of $3.5 \%$.

\subsection{Intervention Costs}

Cost analysis was based on only the costs of the PATHS intervention itself, as resource use data (e.g. use of educational psychologists) were not collected alongside the trial. Micro-costing was used to calculate the incremental costs of the intervention in the trial setting, compared with usual practice. Incremental costs comprised costs of materials, training for teachers and PATHS coaches and ongoing support. Specific cost components, assumptions and sources of unit costs are provided in Table 1, with further detail in Appendix 1 in the Electronic Supplementary Material (ESM).

Costs were assigned as recurrent or non-recurrent (full justifications are provided in Appendix 1 in ESM). As nonrecurrent costs (classroom materials, PATHS coach training and initial full-day classroom teacher training) were likely to provide benefits beyond the trial period, costs were annuitized over their expected life at a discount rate of 3.5\% [47]. The expected life of classroom materials and PATHS coach training was set equal to the expected life of the intervention (5 years) [20]. For initial-full day classroom teacher training, the expected life was set equal to the minimum of either the 5 -year expected intervention life or the expected length of service for a teacher. The latter was estimated as the reciprocal of the annual rate of teacher attrition across both years of the trial, assuming a constant attrition rate.
Costs were reported in $£$ and inflated to year 2018/19 values. Costs incurred beyond the first year of the trial were discounted at a rate of $3.5 \%$.

The total incremental cost of the intervention was derived by summing across all cost elements. Per-child incremental costs were calculated by dividing total cost by the number of children receiving the intervention $(n=2745)$, comprising 2676 study participants and 69 opt-outs from the PATHS arm.

\subsection{Missing Data}

The proportion of children with any missing data on CHU9D utility values over all time points was $51 \%$. We followed recommendations outlined in a recent guide to handling missing data in within-trial CEAs [48].

Descriptive analysis found large differentials in missing data across trial arms, with a smaller proportion of individuals in the control arm providing CHU-9D utility values at all time points (Appendix 2 in the ESM). This reflected increased missingness at the 12- and 24-month follow-ups, primarily because five control schools failed to provide follow-up data. Logistic regression models also identified a range of baseline covariates measured at both the child level (ethnicity, free school meals eligibility, special education needs) and the school level (school size) as predictors of CHU-9D missingness. The existence of any predictors of missingness provided evidence against data being missing completely at random. Logistic regressions also confirmed that the probability of CHU-9D missingness in any given time period significantly decreased with higher CHU-9D utility values in all other waves, providing evidence against covariate-dependent missingness. Data were therefore treated as missing at random, assuming the probability of missingness was independent of unobserved factors, i.e. factors other than baseline covariates and CHU-9D utility values in other waves.

Consistent with the missing at random assumption, multiple imputation (MI) methods using chained equations were employed to handle missing CHU-9D data. Given low levels of domain-specific missingness for the CHU-9D, utility scores were imputed. In total, 50 imputations were chosenapproximately equal to the percentage of cases with missing data [49].

Imputation was carried out separately by trial arm, as the posterior conditional distribution of the missing data given the observed data may differ across treatment arms [50]. Predictors included in the imputation model included the CHU9D utility values at all other time points and a range of childlevel (e.g. sex, year group) and school-level (e.g. school size) covariates, consistent with the main trial [29]. Single-level MI was conducted, assuming all between-school variation in missingness was accounted for by school-level covariates. 


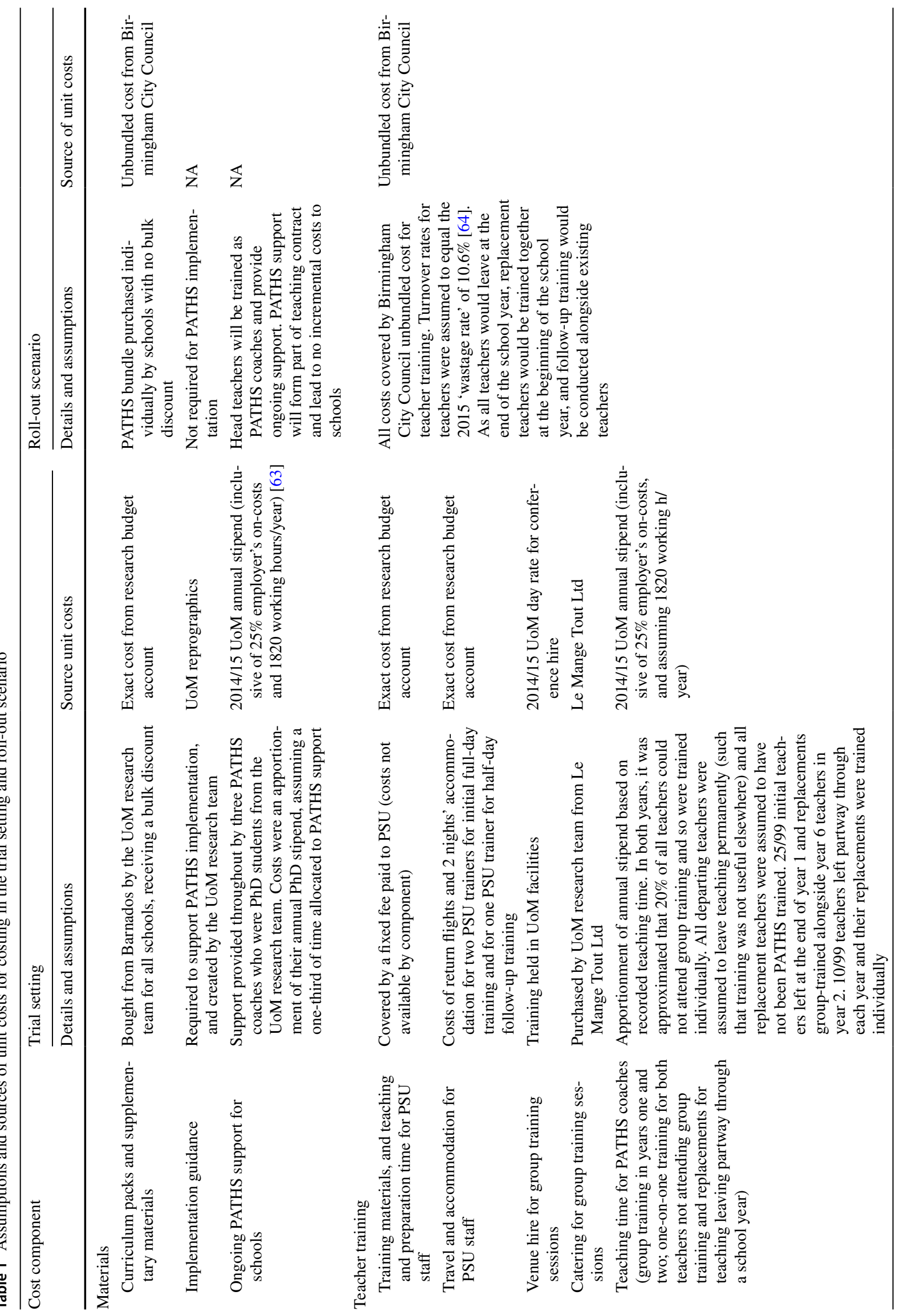




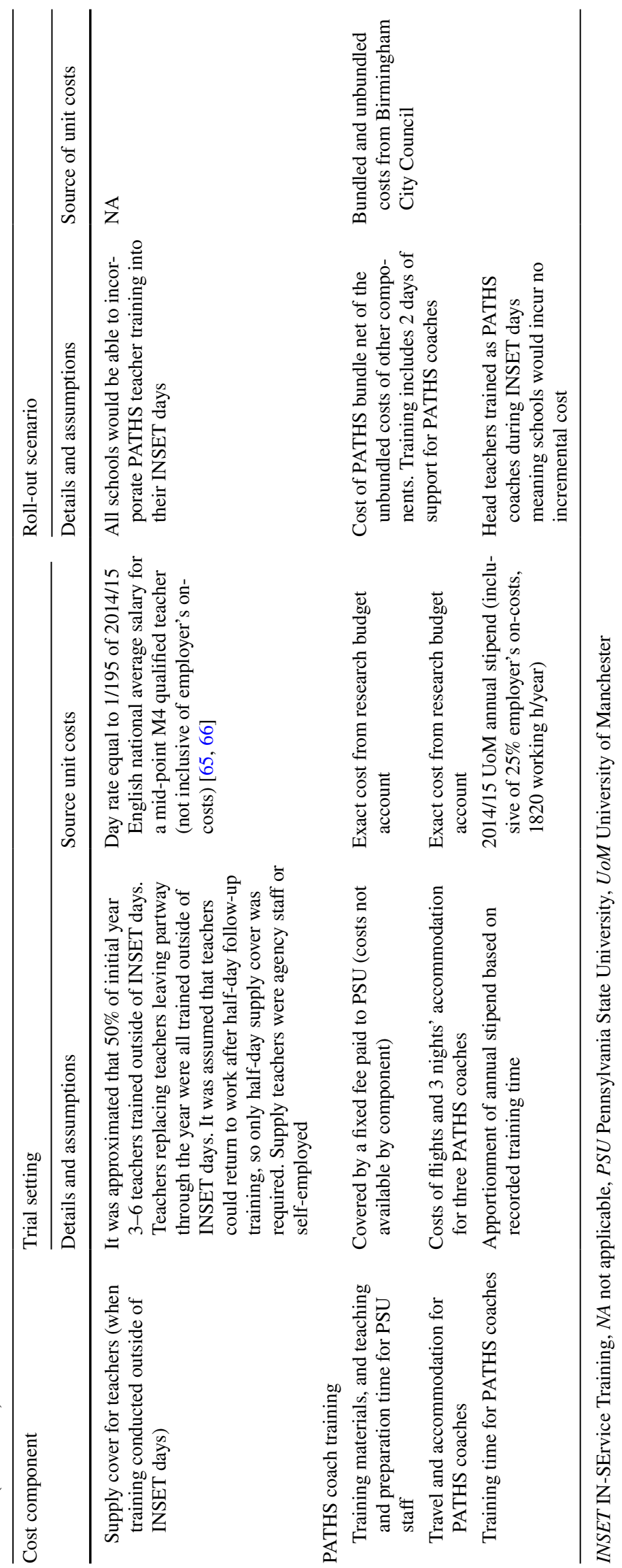


To account for the skewness and multi-modality in the distribution of CHU-9D utility values, predictive mean matching was used to impute CHU-9D utility values [49]. Incremental QALYs were calculated as the mean of incremental QALY estimates generated in each imputed dataset, following Rubin's rule. The validity of the imputation procedure was confirmed by establishing similarity in the distribution of non-missing and imputed QALYs [51].

\subsection{Data Analysis}

Incremental costs and QALYs were modelled separately. The incremental cost of PATHS was calculated as the simple difference between costs in the treatment and control arms and was equal to the average child-level incremental intervention costs. To estimate incremental QALYs, childlevel random intercept models were used to account for clustering of outcomes at school level. Explanatory variables comprised intervention status (PATHS vs. control), baseline CHU-9D utility values [46] and the child-level and schoollevel covariates used in the imputation model.

\subsection{Presentation of Results}

The main trial found PATHS led to very small improvements in children's psychological wellbeing and no improvements in social skills and mental health problems relating to internalising and externalising behaviour [29]. Negative incremental QALY estimates were therefore possible. Consequently, incremental net benefits (INBs) were chosen over incremental cost-effectiveness ratios (ICERs) to present results [52] and were calculated as follows:

$\operatorname{INB}(\lambda)=\lambda\left(\mathrm{QALY}_{p}-\mathrm{QALY}_{u}\right)-\left(\operatorname{cost}_{p}-\operatorname{cost}_{u}\right)$

$p$ and $u$ refer to intervention and control arms, respectively, and $\lambda$ denotes the cost-effectiveness threshold, representing willingness to pay (WTP) for an additional QALY. PATHS was deemed cost effective at a given threshold if the INB was positive. INBs were estimated for thresholds ranging from $£ 0$ to 150,000 , increasing in $£ 1000$ increments. In the UK, NICE sets this threshold at $£ 20,000-30,000$ [28].

\subsection{Identifying Sample Uncertainty}

Uncertainty was examined via non-parametric bootstrapping techniques using 10,000 iterations. This was combined with the MI methods as follows. First, for each bootstrap replication, a sample size of 5218 was randomly drawn with replacement from each of the 50 imputed datasets. Incremental QALYs and costs were re-estimated within each sample and Rubin's rules used to combine incremental statistics across samples in each imputed dataset to form average statistics for the bootstrap replication. INBs were then calculated for each value of the threshold within each bootstrap replication, and standard bootstrap methods were used to construct confidence intervals [53]. These estimates were then used to construct cost-effectiveness acceptability curves (CEACs).

\subsection{One-Way Sensitivity Analyses}

We undertook five one-way sensitivitiy analyses. First, we examined the robustness of results to using alternative preference weights for constructing CHU-9D utility values derived using a best-worst scaling discrete-choice experiment in an Australian adolescent sample, which assign greater weights to the CHU-9D mental health domains [54]. Second, we examined the effect of performing a complete case analysis where all observations with missing data were removed. Third, we explored the impact of changing the expected life of the intervention from 5 to 10 years when annuitizing non-recurrent costs.

Fourth, we considered the effects of including costs relating to classroom teachers' time spent training, preparing for and delivering the intervention as previous studies have treated these costs as incremental [20,55]. These costs were not considered as incremental in the base-case analysis as the fixed-length school day means PATHS necessarily displaced other components of the school curriculum that required equal time resources and therefore consumed identical time resources as in usual practice [56]. Teacher's salary costs are currently paid by the UK Department for Education. These costs would therefore only be considered incremental under a UK health sector perspective if the NHS were to agree to fund the costs of the proportion of the school day required for PATHS implementation. We examined the effects of assuming $40 \mathrm{~min}$ [56] or $45 \mathrm{~min}$ [20] of preparation time per teacher per week.

Finally, we costed the intervention in a hypothetical scenario similar to that in the event of nationwide roll-out, given that these costs would likely differ from those incurred in the trial. The assumptions in the roll-out scenario are presented in Table 1 and in Appendix 3 in the ESM. Costs were based on those charged by Birmingham City Council, as they were the only council providing a traded PATHS service with English schools during the implementation period [56]. This provided a total bundled cost of PATHS for a single-form entry school with seven year groups (reception to year 6). This cost included (1) a curriculum pack and supplementary materials for each class, (2) initial training for seven teachers, (3) training of a PATHS coach/co-ordinator (usually a head teacher) and (4) 2 days of PATHS coaching support (assumed to occur in the first year and be non-recurrent). Unbundled costs for curriculum packs and supplementary material and full-day and half-day teacher training for seven 
teachers were also provided. Total costs were divided by seven to get a total cost per class and multiplied by the number of classes in the PATHS arm of the trial to get a cost equivalent to the size of the PATHS school sample. This cost was then divided by the number of children receiving the PATHS intervention to get an equivalent cost per pupil.

\section{Results}

\subsection{School and Child Characteristics}

Table 2 summarises the characteristics of all pupils in the 45 schools (PATHS: $n=23$; control: $n=22$ ) and the 5218 pupils (PATHS: $n=2676$; control: $n=2542$ ) in the trial. Randomisation generally achieved good balance across trial arms on school characteristics and trial participant characteristics, although PATHS schools had more pupils and a higher percentage of pupils with EAL than did control schools, and children in the PATHS arm were more likely to be eligible for free school meals and to be from a minority ethnic group.

\subsection{Incremental Intervention Costs}

Micro-costing estimates for the base-case scenario are summarised in Table 3. Incremental non-recurrent costs associated with the PATHS materials and training for PATHS coaches and original teachers totalled $£ 39,323$ for the PATHS schools. Incremental recurrent costs totalled $£ 48,550$, driven primarily by the costs of ongoing support from PATHS coaches and follow-up teacher training. Overall, the total incremental cost of the intervention was $£ 87,873$, corresponding to an incremental cost per child of $£ 32.01$ for the 2745 receiving the intervention.

\subsection{Incremental Quality-Adjusted Life-Years}

Average CHU-9D utility scores at baseline and each followup, and QALYs gained over the 2-year trial period, were higher for the PATHS arm than the usual practice arm after accounting for missing data (Table 4). Adjusting for baseline CHU-9D utility scores and child- and school-level covariates in a random intercept model, adjusted mean incremental QALYs for PATHS were 0.0019 (95\% confidence interval [CI] 0.0009-0.0029).

\subsection{Cost-Effectiveness}

Cost-effectiveness evidence for PATHS in the base-case analysis is summarised in Table 4 and Fig. 1. Assuming the minimum threshold used by NICE of $£ 20,000$ per QALY, the expected INB of introducing PATHS was $£ 5.56$ per child
Table 2 Sample school and pupil characteristics by trial arm

\begin{tabular}{lll}
\hline Characteristics & PATHS schools & Control schools \\
\hline Schools $^{\mathrm{a}}$ & $n=23$ & $n=22$ \\
Average number of pupils & 313.26 & 287.36 \\
\% of pupils eligible for free school meals & 30.13 & 30.86 \\
$\%$ of pupils from white ethnic group & 66.96 & 65.72 \\
$\%$ of pupils with English as an additional language & 24.65 & 21.99 \\
$\%$ of pupils who have been absent from school & 5.60 & 5.06 \\
$\%$ of pupils with special education needs & 17.28 & 16.59 \\
$\%$ of pupils who have been excluded & 0.50 & 0.46 \\
Pupils & $n=2676$ & $n=2542$ \\
Sex (base = female) & $1335(49.9 \%)$ & $1346(53 \%)$ \\
Year group & & \\
Year 3 & $974(36.4 \%)$ & $908(35.7 \%)$ \\
Year 4 & $855(32 \%)$ & $850(33.4 \%)$ \\
Year 5 & $847(31.7 \%)$ & $784(30.8 \%)$ \\
Free school meal eligibility (base =no) & $837(32.4 \%)$ & $696(28.5 \%)$ \\
Minority ethnic group (base = white) & $731(30.3 \%)$ & $687(27 \%)$ \\
English as an additional language (base =no) & $568(23.3 \%)$ & $562(21.8 \%)$ \\
Special Educational Needs provision (base =no) & $509(20.9 \%)$ & $483(18.7 \%)$ \\
CHU-9D utility value at baseline & $0.828 \pm 0.122$ & $0.841 \pm 0.118$ \\
\hline
\end{tabular}

Data are presented as $\mathrm{n}(\%)$ or mean \pm standard deviation unless otherwise indicated

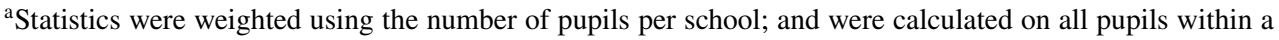
school and not just those involved in the trial

${ }^{\mathrm{b}}$ Statistics were calculated with all available data for each variable 
Table 3 Incremental costs of the Promoting Alternative Thinking Strategies (PATHS) intervention

\begin{tabular}{|c|c|}
\hline Costs & $\begin{array}{l}\text { Total costs } \\
(£, 2018 / 19 \\
\text { values) }\end{array}$ \\
\hline \multicolumn{2}{|l|}{ Non-recurrent costs } \\
\hline Materials $^{\mathrm{a}}$ & 17,007 \\
\hline PATHS coach training ${ }^{\mathrm{a}}$ & 4002 \\
\hline Initial full-day teacher training for original teachers ${ }^{\mathrm{b}}$ & 18,294 \\
\hline Total non-recurrent costs & 39,323 \\
\hline \multicolumn{2}{|l|}{ Recurrent costs } \\
\hline Ongoing support & 25,916 \\
\hline Follow-up half-day teacher training for original teachers & 12,501 \\
\hline \multicolumn{2}{|c|}{$\begin{array}{l}\text { Training replacements for year } 4 \text { and } 5 \text { teachers leaving at the end of the school year } \\
\text { (trained with year } 6 \text { teachers in year 2) }\end{array}$} \\
\hline Initial full-day training ${ }^{c}$ & 1664 \\
\hline Follow-up half-day training & 1302 \\
\hline \multicolumn{2}{|l|}{ Training replacements for teachers leaving mid-school year } \\
\hline Initial full-day training ${ }^{\mathrm{c}}$ & 4278 \\
\hline Follow-up half-day training & 2889 \\
\hline Total recurrent costs & 48,550 \\
\hline Total intervention costs (all schools) & 87,873 \\
\hline Cost per child & 32.01 \\
\hline
\end{tabular}

All costs discounted at $3.5 \%$ per year and inflated to 2018/19 values using the retail price index

${ }^{a}$ Annuitized over 5-year expected intervention life at $3.5 \%$ per year

${ }^{b}$ Annuitized over the 2.75-year within-trial expected length of teacher service (given $36.36 \%$ teacher turnover rate) at $3.5 \%$ per year

${ }^{\mathrm{c}}$ Although recurrent, this training is still annuitized as it will have an effect beyond the trial period

\begin{tabular}{|c|c|c|}
\hline & PATHS $(n=2676)$ & Control $(n=2542)$ \\
\hline \multicolumn{3}{|l|}{ HRQoL } \\
\hline Baseline & $0.839 \pm 0.003$ & $0.827 \pm 0.003$ \\
\hline 1-year follow-up & $0.855 \pm 0.002$ & $0.853 \pm 0.003$ \\
\hline 2-year follow-up & $0.872 \pm 0.002$ & $0.863 \pm 0.003$ \\
\hline QALYs & $1.711 \pm 0.004$ & $1.698 \pm 0.004$ \\
\hline \multicolumn{3}{|l|}{ Incremental QALYs } \\
\hline Unadjusted & $0.013 \pm 0.005$ & \\
\hline Adjusted $^{\mathrm{a}}$ & 0.0019 (95\% CI $0.0009-0.0029)$ & \\
\hline Costs $(£)$ & $29.93 \pm 0$ & $0 \pm 0$ \\
\hline Incremental costs & $29.93 \pm 0$ & \\
\hline $\begin{array}{l}\text { Incremental net benefit }(\mathfrak{f})(\lambda= \\
£ 20,00)^{\mathrm{b}}\end{array}$ & $7.644(95 \% \mathrm{CI}-12.60$ to 27.89$)$ & \\
\hline
\end{tabular}

Values are presented as mean \pm standard error

$C I$ confidence interval, $H R Q O L$ health-related quality of life, INB incremental net benefit, PATHS Promoting Alternative Thinking Strategies, $Q A L Y$ quality-adjusted life-year

a Adjusting for baseline HRQoL and child- and school-level covariates in a random effects intercept model. CIs derived from 10,000 bootstrap replications from 50 imputed datasets using the standard normal method

${ }^{\mathrm{b}} \mathrm{CIs}$ derived from 10,000 bootstrap replications from 50 imputed datasets using the standard normal method
(95\% CI -14.68 to 25.81 ), and the probability of PATHS resulting in a positive INB, and therefore being cost effective, was approximately $84 \%$ (Fig. 1). The probability of cost effectiveness exceeds $50 \%$ for WTP thresholds beyond $£ 15,100$. 
Fig. 1 Cost-effectiveness acceptability curves of the PATHS curriculum versus usual practice: base-case and sensitivity analysis. $C H U-9 D$ Child Health Utility-Nine Dimensions, PATHS promoting alternative thinking strategies, Prep preparation
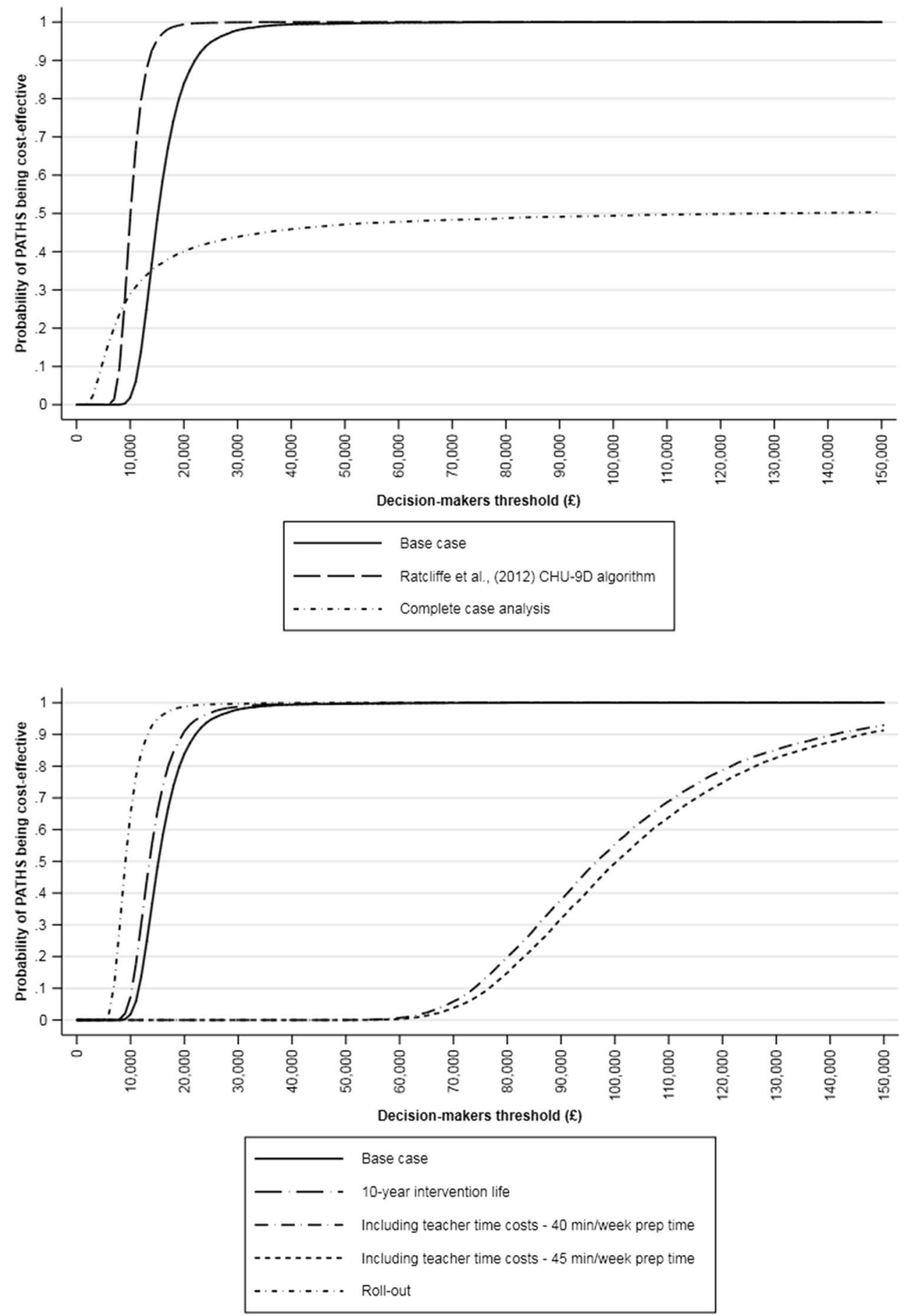

\subsection{Sensitivity Analyses}

Figure 1 presents CEACs detailing the sensitivity analyses. Using the best-worst scaling algorithm to derive CHU-9D utility values increased mean incremental QALYs to 0.0028 (95\% CI 0.0015-0.0040), increasing the probability of cost effectiveness at all threshold values and increasing the probability of PATHS producing a positive INB at a WTP of $£ 20,000$ per QALY to $99.4 \%$ (Fig. 1).

Removing observations with at least partial missing data in a complete case analysis resulted in a small negative estimate of mean incremental QALYs $(-0.000028$; 95\% $\mathrm{CI}-0.0101$ to 0.0101$)$. The resulting probability of cost effectiveness at the $£ 20,000$ per QALY threshold was $40 \%$. 
Assuming a 10-year rather than 5-year expected intervention life led to a small reduction in incremental costs of $£ 3.50$ per child (Table 5 ), increasing the probability of PATHS being cost effective at a WTP of $£ 20,000$ per QALY to $91.0 \%$.

Inclusion of teacher salary costs had a substantial impact on both incremental costs and INB statistics irrespective of the assumption made regarding the required lesson preparation time for PATHS lessons. Incremental costs increased to over $£ 200$ per child (Table 5) and a $0 \%$ probability of PATHS being cost effective at conventional UK thresholds of WTP for a QALY.

In the roll-out scenario, the per-child incremental cost of the intervention was estimated to reduce from the base-case cost of $£ 32.01$ to $£ 19.07$. At this cost, the probability of PATHS being cost effective was $98.7 \%$ for a WTP threshold of $£ 20,000$ per QALY and exceeded $50 \%$ for WTP thresholds beyond $£ 9000$.

\section{Discussion}

This study is the first prospective economic evaluation of an SEL intervention examining impacts on HRQoL. It was conducted via a cluster-randomised controlled trial in the UK and independently of intervention developers. It also represents one of the first economic evaluations in which HRQoL was measured using the CHU-9D and grows the limited number of economic evaluations of paediatric interventions using preference-based instruments of HRQoL designed specifically for children [57].

The base-case analysis indicated that PATHS led to a small increase in QALYs and, as a result of small incremental intervention costs, that PATHS is likely to be cost effective at conventional thresholds of WTP of $£ 20,000$ and $£ 30,000$ per QALY used in the UK [28]. However, the probability of cost effectiveness would decrease to approximately $25 \%$ assuming a proposed lower threshold of $£ 12,936$ per QALY [58].

The demonstrated small, positive effects of PATHS on HRQoL are consistent with the positive effects on other child outcomes reported in US-based developer-led trials $[15-17,19,21,23,24]$. However, they are inconsistent with the largely null findings from international independent RCTs examining impacts on social and emotional skills and mental health $[18,22,59]$. The CHU-9D may be capturing wider health benefits of PATHS and/or the CHU-9D preference weights may be placing higher weights on the outcomes improved by PATHS.

Our sensitivity analyses offer key information for policy makers deciding whether to recommend PATHS for nationwide roll-out. Whether PATHS is cost effective depends most on whether costs of teacher preparation and delivery time fall on the decision maker. By providing point estimates for costs, QALYs and INBs, alongside CEACs, we provide the opportunity for decision makers to select results aligned with their own WTP and the assumptions most applicable to their setting.

This research also highlighted the considerable difficulty in costing an intervention in a school setting. Even ignoring the idiosyncrasies of this particular trial, teacher turnover is commonplace in all schools but have not been considered in previous studies of this type [20,55]. In these studies, non-recurrent training costs are annuitized over the expected life of the intervention, and an implicit assumption is made that the teacher turnover rate is zero during this period. Furthermore, the cost of training replacement teachers has not been considered. Given this, a failure to recognise teacher turnover has likely led to an underestimation of the costs of PATHS interventions.

The study has a number of limitations. First, no data on the use of either school-based health services, such as education psychologists and art/drama therapy, or external health services, such as visits to hospitals, general practitioners and psychiatrists, were collected alongside the trial. It is unclear how the inclusion of these costs would have impacted the incremental costs of the intervention. Improvements in QALYs could have led to a reduction in the need to access curative services. However, it is possible that PATHS led to an identification of unmet need, particularly through increased awareness of socio-emotional disorders, leading to an increase in the use of these services. Positive incremental QALYs could partially reflect this increase in use.

Second, a UK health sector perspective was chosen, consistent with the perspective typically used in CEAs. A cost-consequence analysis using a public sector perspective could have captured benefits falling in sectors other than health [60]. However, the main trial found no statistically significant effects on educational attainment or the rate of exclusions [29], suggesting that the potential for wider societal benefits may be limited. In addition, given the absence of data on resource use, incremental costs from a public sector perspective would be identical to those from a healthcare sector perspective in this study. Furthermore, cost-consequence analysis does not enable easy comparisons of interventions with disparate outcomes, whereas CUA provides an accepted benchmark with which to compare value for money. This evaluation was also constrained by its time horizon, which was set equal to the follow-up period of the main trial. Future research could use parameters estimated in this study to conduct a model-based evaluation of PATHS' longer-term cost effectiveness.

Finally, there are several risks to the study's external validity, which may have led to the effects of PATHS being underestimated. First, the annual teacher turnover rate in the trial (36\%) was much higher than the national average (11\%). 
Table 5 Incremental costs of the Promoting Alternative Thinking Strategies (PATHS) intervention in sensitivity analyses: (1) 10-year intervention life, (2) inclusion of teacher's salary costs

\begin{tabular}{|c|c|}
\hline Scenario & $\begin{array}{l}\text { Total costs ( } £ \text {, year } \\
2018 / 19 \text { values) }\end{array}$ \\
\hline \multicolumn{2}{|l|}{ (1) 10 -year intervention life } \\
\hline \multicolumn{2}{|l|}{ Materials } \\
\hline Annuitised over 5-year intervention life & 17,007 \\
\hline Annuitised over 10-year intervention life & 9233 \\
\hline \multicolumn{2}{|l|}{ PATHS coach training } \\
\hline Annuitised over 5-year intervention life & 4022 \\
\hline Annuitised over 10-year intervention life & 2184 \\
\hline Other intervention costs & 66,844 \\
\hline Total intervention costs -10 -year intervention life & 78,260 \\
\hline Cost per child-10-year intervention life & 28.51 \\
\hline \multicolumn{2}{|l|}{ (2) Including teacher's salary costs } \\
\hline \multicolumn{2}{|l|}{ Non-recurrent costs } \\
\hline Original classroom teacher time during initial full-day training & 21,570 \\
\hline \multicolumn{2}{|l|}{ Recurrent costs } \\
\hline Original classroom teacher time during follow-up half-day training & 17,162 \\
\hline Replacement classroom teacher time during initial full-day training & 4685 \\
\hline Replacement classroom teacher time during follow-up half-day training & 3727 \\
\hline Classroom teacher time during lesson delivery & 255,228 \\
\hline \multicolumn{2}{|l|}{ Classroom teacher time during lesson preperation } \\
\hline $40 \mathrm{~min} /$ week lesson preparation & 170,152 \\
\hline $45 \mathrm{~min} /$ week lesson preparation & 191,142 \\
\hline \multicolumn{2}{|l|}{ Total cost of teacher's time } \\
\hline $40 \mathrm{~min} /$ week lesson preparation & 472,523 \\
\hline $45 \mathrm{~min} /$ week lesson preparation & 493,792 \\
\hline Other intervention costs & 87,873 \\
\hline \multicolumn{2}{|l|}{ Total intervention costs } \\
\hline $40 \mathrm{~min} /$ week lesson preparation & 560,396 \\
\hline $45 \mathrm{~min} /$ week lesson preparation & 581,665 \\
\hline \multicolumn{2}{|l|}{ Cost per child } \\
\hline $40 \mathrm{~min} /$ week lesson preparation & 204.15 \\
\hline $45 \mathrm{~min} /$ week lesson preparation & 211.90 \\
\hline \multicolumn{2}{|l|}{ (3) Roll-out scenario } \\
\hline \multicolumn{2}{|l|}{ Costs for a single-form entry, seven year group, school } \\
\hline \multicolumn{2}{|l|}{ Non-recurrent costs } \\
\hline Materials ${ }^{\mathrm{a}}$ & 1023 \\
\hline PATHS coach training and initial support $\mathrm{t}^{\mathrm{a}}$ & 1916 \\
\hline Initial full-day training for original classroom teachers ${ }^{\mathrm{a}}$ & 244 \\
\hline Total non-recurrent costs & 3183 \\
\hline \multicolumn{2}{|l|}{ Recurrent costs } \\
\hline Half-day follow-up training & 275 \\
\hline Initial full-day training for replacement teachers ${ }^{\mathrm{b}}$ & 244 \\
\hline Total recurrent costs & 519 \\
\hline Total cost for single-form entry, seven year group, school & 3701 \\
\hline Price per class & 528.71 \\
\hline Total intervention cost for PATHS sample (99 classes) & 52,343 \\
\hline Cost per child & 19.07 \\
\hline
\end{tabular}

PATHS Promoting Alternative Thinking Strategies

All costs discounted a $3.5 \% / y e a r$, and inflated to 2018/19 prices using the retail price index where appropriate

${ }^{a}$ Using the national wastage rate of $10.6 \%$, the expected length of service for a teacher is 9.43 years. As this is less than the 5-year expected life of the intervention, all non-recurrent costs are annuitised over a 5-year intervention life at $3.5 \%$ per year

${ }^{\mathrm{b}}$ Although recurrent, this training is still annuitized as it will have an effect beyond the trial period 
If teacher continuity is positively correlated with implementation quality, then this may have resulted in reduced effectivenes compared with a roll-out scenario. Furthermore, as trial participants were not blinded to treatment, treatment spillovers and compensatory rivalry [61] may have led to a further underestimation of mean incremental QALYs and the INB. However, this issue is near impossible to avoid in school-based trials such as this [62]. Lastly, teacher training and ongoing support during the trial was conducted by expert staff from PSU and by members of the research team. If the quality of teacher training by school staff differs from that by PSU staff in a roll-out scenario, then the effectiveness and cost effectiveness of the intervention would be affected.

\section{Conclusion}

The findings of this economic analysis based on data collected in a large, independent, cluster-randomised controlled trial suggest that PATHS has the potential to be cost effective. However, there is considerable uncertainty around this conclusion; results are sensitive to the inclusion of costs associated with teachers' time spent in training and delivery. Information presented in this study can support decision makers allocating scarce health resources and provide cost and benefit estimates that can be incorporated into modelbased evaluations to assess the long-term cost effectiveness of PATHS.

Acknowledgements The authors are grateful to experts Professor Katherine Payne, Professor Rachel Elliot, Professor Linda Davies, Mr. Alexander Thompson and Dr. Sean Gavan at The University of Manchester for providing their thoughts and feedback on our analytical approach.

\section{Compliance with Ethical Standards}

Funding The research presented in this manuscript was funded by the National Institute for Health Research (grant ref: 10/3006/01). The views expressed in this article are those of the authors and not of the funding body.

Conflicts of interest Alex J Turner, Matt Sutton, Mark Harrison, Alexandra Hennessey and Neil Humphrey have no conflicts of interest that are directly relevant to the content of this article.

Author Contributions Neil Humphrey conceived the study and designed the trial. Alexandra Hennessey was involved in the implementation of the trial and collection of data. Alex $\mathbf{J}$ Turner designed the economic methodology alongside Matt Sutton and Mark Harrison. Alex J Turner undertook the analysis and wrote the manuscript. All authors assisted with the interpretation of results and critically reviewed the manuscript.

Data Availability Data are available from the authors upon request.
Open Access This article is distributed under the terms of the Creative Commons Attribution-NonCommercial 4.0 International License (http://creativecommons.org/licenses/by-nc/4.0/), which permits any noncommercial use, distribution, and reproduction in any medium, provided you give appropriate credit to the original author(s) and the source, provide a link to the Creative Commons license, and indicate if changes were made.

\section{References}

1. Denham SA, Ferrier DE, Howarth GZ, Herndon KJ, Bassett $\mathrm{HH}$. Key considerations in assessing young children's emotional competence. Camb J Educ. 2016;46:299-317. https://doi. org/10.1080/0305764X.2016.1146659.

2. Goodman A, Joshi H, Nasim B, Tyler C. Social and emotional skills in childhood and their long-term efects on adult life. London: Institute of Education; 2015.

3. The Organisation for Economic Co-operation and Development (OECD). Skills for social progress: the power of social and emotional skills. 2015. https://doi.org/10.1787/9789264226159-en.

4. National Institute for Health and Care Excellence (NICE). Social and emotional wellbeing: early years. London: NICE; 2012.

5. National Institute for Health and Care Excellence (NICE). Social and emotional wellbeing in secondary education. London: NICE; 2009.

6. National Institute for Health and Care Excellence (NICE). Social and emotional wellbeing in primary education. London: NICE; 2008

7. Weissberg RP, Durlak JA, Domitrovich CE, Gullotta TP. Social and emotional learning: past, present, and future. In: Durlak A, Domitrovich CE, Weissberg RP, Gullotta TP, editors. Handb. Soc. Emot. Learn. Res. Pract. New York: Guilford Press; 2015. p. 3-19.

8. Durlak JA, Weissberg RP, Dymnicki AB, Taylor RD, Schellinger KB. The impact of enhancing students' social and emotional learning: a meta-analysis of school-based universal interventions. Child Dev. 2011;82:405-32. https://doi.org/10.111 1/j.1467-8624.2010.01564.x.

9. Sklad M, Diekstra R, De Ritter M, Ben J, Gravesteijn C. Effectiveness of school-based universal social, emotional, and behavioral programs: do they enhance students' development in the area of skills, behavior and adjustment? Psychol Sch. 2012;49:892-909. https://doi.org/10.1002/pits.

10. Wigelsworth M, Lendrum A, Oldfield J, Scott A, ten Bokkel I, Tate K, et al. The impact of trial stage, developer involvement and international transferability on universal social and emotional learning programme outcomes: a meta-analysis. Camb J Educ. 2016;46:347-76. https://doi.org/10.1080/0305764X.2016.11957 91.

11. Corcoran RP, Cheung ACK, Kim E, Xie C. Effective universal school-based social and emotional learning programs for improving academic achievement: a systematic review and meta-analysis of 50 years of research. Educ Res Rev. 2018;25:56-72. https://doi. org/10.1016/j.edurev.2017.12.001.

12. Taylor RD, Oberle E, Durlak JA, Weissberg RP. Promoting positive youth development through school-based social and emotional learning interventions: a meta-analysis of follow-up effects. Child Dev. 2017;88:1156-71. https://doi.org/10.1111/cdev.12864

13. Allen G. Early intervention: the next steps. London: Cabinet Office; 2011.

14. Greenberg MT, Kusché CA. Promoting social and emotional development in deaf children: the PATHS project. Washington: University of Washington Press; 1993. 
15. Greenberg MT, Kusche CA, Cook ET, Quamma JP. Promoting emotional competence in school-aged children: the effects of the PATHS curriculum. Dev Psychopathol. 1995;7:117-36. https:// doi.org/10.1017/s0954579400006374.

16. Conduct Problems Prevention Research Group. Initial impact of the Fast track prevention trial for conduct problems: I. The highrisk sample. J Consult Clin Psychol. 1999;67:631-47.

17. Domitrovich CE, Cortes RC, Greenberg MT. Improving young children's social and emotional competence: a randomized trial of the preschool "PATHS" curriculum. J Prim Prev. 2007;28:67-91. https://doi.org/10.1007/s10935-007-0081-0.

18. Social and Character Development Research Consortium. Efficacy of school-wide programs to promote social and character development and reduce problem behavior in elementary school children. Washington DC. 2010. Doi: NCER 2011-2001.

19. Ross SM, Sheard MK, Cheung A, Elliott L, Slavin R. Promoting primary pupils' social-emotional learning and pro-social behaviour: longitudinal evaluation of the Together 4 All Programme in Northern Ireland. Eff Educ. 2011;3:61-81. https:// doi.org/10.1080/19415532.2012.665773.

20. Berry V, Axford N, Blower S, Taylor RS, Edwards RT, Tobin K, et al. The effectiveness and micro-costing analysis of a universal, school-based, social-emotional learning programme in the UK: a cluster-randomised controlled trial. School Ment Health. 2016;8:238-56. https://doi.org/10.1007/s12310-015-9160-1.

21. Schonfeld DJ, Adams RE, Fredstrom BK, Weissberg RP, Gilman $\mathrm{R}$, Voyce $\mathrm{C}$, et al. Cluster-randomized trial demonstrating impact on academic achievement of elementary social-emotional learning. Sch Psychol Q. 2015;30:406-20.

22. Malti T, Ribeaud D, Eisner MP. The effectiveness of two universal preventive interventions in reducing children's externalizing behavior: a cluster randomized controlled trial. J Clin Child Adolesc Psychol. 2011;40:677-92. https://doi.org/10.1080/15374 416.2011.597084.

23. Morris P, Mattera SK, Castell N, Bangser M, Bierman KL, Raver C. Impact findings from the Head Start CARES demonstration: national evaluation of three approaches to improving preschoolers' social and emotional competence. Washington, DC: U.S. Department of Health and Human Services, Office of Planning, Research, and Evaluation, Administration for Children and Families; 2014

24. Novak M, Mihić J, Bašić J, Nix RL. PATHS in Croatia: a schoolbased randomised-controlled trial of a social and emotional learning curriculum. Int J Psychol. 2016;1:1. https://doi.org/10.1002/ ijop.12262 (Early View).

25. Humphrey N, Barlow A, Wigelsworth M, Lendrum A, Pert $\mathrm{K}$, Joyce $\mathrm{C}$, et al. A cluster randomized controlled trial of the Promoting Alternative Thinking Strategies (PATHS) curriculum. J Sch Psychol. 2016;58:73-89. https://doi.org/10.1016/j. jsp.2016.07.002.

26. McCabe C. A systematic review of cost-effectiveness analyses of whole school and focused primary school-based interventions to promote children's mental health. Leeds: Leeds Institute of Health Sciences, University of Leeds; 2007.

27. Hunter LJ, DiPerna JC, Hart SC, Crowley M. At what cost? Examining the cost effectiveness of a universal social-emotional learning program. Sch Psychol Q. 2018;33:147-54. https://doi. org/10.1037/spq0000232.

28. National Institute for Health and Care Excellence (NICE). Guide to the methods of technology appraisal 2013. London: NICE; 2013.

29. Humphrey N, Hennessey A, Lendrum A, Wigelsworth M, Turner AJ, Panayiotou M, et al. Evaluating the efficacy of the Promoting Alternative Thinking Strategies (PATHS) curriculum in promoting social and emotional wellbeing among children in primary school: a cluster randomised controlled trial, process evaluation, and economic analysis. Public Heal Res. 2018. (First Look).

30. Goodman R. The strengths and difficulties questionnaire: a research note. J Child Psychol Psychiatry. 1997;38:581-6. https ://doi.org/10.1111/j.1469-7610.1997.tb01545.x.

31. Gresham F, Elliot S. Social skills improvement system: rating scales manual. Minneapolis, MN: Pearson Assessments; 2008.

32. Department for Education. Schools, pupils and their characteristics. London: Department for Education; 2010.

33. Department for Education. Children with special educational needs: an analysis. London: Department for Education; 2012.

34. Department for Education. National curriculum assessments at Key Stage 2: 2012 to 2013. London: Department for Education. 2013.

35. Department for Education. Pupil absence in schools in England: 2012 to 2013. London: Department for Education; 2014.

36. Centre for the Study and Prevention of Violence. Model Programs Fact Sheet: Promoting Alternative Thinking Strategies. Denver, CO. 2006.

37. Department for Children S and F. Secondary social and emotional aspects of learning (SEAL) programme: guidance. Nottingham, England. 2007.

38. National Centre for Social Research. Evaluation of the National Healthy Schools Programme. London. 2013.

39. Mosley J. Quality circle time in the primary classroom: your essential guide to enhancing self-esteem, self-discipline and positive relationship. Cambridge. 1996.

40. Bennathan M, Boxall M. Effective intervention in primary schools: nurture groups. 2nd ed. New York: Routledge; 2012.

41. Department for Children Schools and Families. Targeted mental health in schools project: using the evidence to inform your approach: a Practical guide for headteachers and commissioners. 2008, pp 1-104.

42. Macready T. Learning social responsibility in schools: a restorative practice. Educ Psychol Pract. 2009;25:211-20. https://doi. org/10.1080/02667360903151767.

43. Stevens K. Working with children to develop dimensions for a preference based generic paediatric, health related quality of life measure. Qual Health Res. 2010;20:340-51. https://doi. org/10.1177/1049732309358328.

44. Stevens K. Assessing the performance of a new generic measure of health-related quality of life for children and refining it for use in health state valuation. Appl Health Econ Health Policy. 2011;9:157-69. https://doi.org/10.2165/11587350-00000000000000 .

45. Stevens K. Valuation of the child health utility 9D index. Pharmacoeconomics. 2012;30:729-47. https://doi.org/10.2165/11599120.

46. Manca A, Hawkins N, Sculpher MJ. Estimating mean QALYs in trial-based cost-effectiveness analysis: the importance of controlling for baseline utility. Health Econ. 2005;14:487-96. https://doi. org/10.1002/hec. 944 .

47. Netten A, Knight J. Annuitizing the human capital investment costs of health service professionals. Health Econ. 1999;8:245-55.

48. Faria R, Gomes M, Epstein D, White IR. A guide to handling missing data in cost-effectiveness analysis conducted within randomised controlled trials. Pharmacoeconomics. 2014;32:1157-70. https://doi.org/10.1007/s40273-014-0193-3.

49. White IR, Royston P, Wood AM. Multiple imputation using chained equations: issues and guidance for practice. Stat Med. 2011;30:377-99. https://doi.org/10.1002/sim.4067.

50. Carpenter JR, Kenward MG. Multiple imputation and its application. Chichester, UK: Wiley. 2013. https://doi.org/10.1002/97811 19942283.

51. Rubin DB, Schenker N. Multiple imputation in healthcare databases: an overview and some applications. Stat Med. 1991;10:585-98. https://doi.org/10.1002/sim.4780100410. 
52. Briggs AH, O’Brien BJ. Analysis of uncertainty in health care cost-effectiveness studies: an introduction to statistical issues and methods. Stat Methods Med Res. 2002;11:455-68.

53. Nixon RM, Wonderling D, Grieve RD. Non-parametric methods for cost-effectiveness analysis: the central limit theorem and the bootstrap compared. Health Econ. 2010;19:316-33. https://doi. org/10.1002/hec. 1477 .

54. Ratcliffe J, Flynn T, Terlich F, Stevens K, Brazier J, Sawyer M. Developing adolescent-specific health state values for economic evaluation: an application of profile case best-worst scaling to the child health utility 9D. Pharmacoeconomics. 2012;30:713-27. https://doi.org/10.2165/11597900.

55. McCabe C. Estimating the short term cost effectiveness of a mental health promotion intervention in primary schools. Natl Inst Heal Clin Excell. 2008;2008:1-28.

56. PATHS to Success Research Team. Promoting alternative thinking strategies (PATHS): evaluation report and executive summary. London. 2015.

57. Adlard N, Kinghorn P, Frew E. Is the UK NICE "reference case" influencing the practice of pediatric quality-adjusted lifeyear measurement within economic evaluations? Value Heal. 2014;17:454-61. https://doi.org/10.1016/j.jval.2014.02.007.

58. Claxton K, Martin S, Soares M, Rice N, Spackman E, Hinde $S$, et al. Methods for the estimation of the National Institute for Health and care excellence cost-effectiveness threshold. Health
Technol Assess (Rockv). 2015;19:1-503. https://doi.org/10.3310/ hta19140.

59. Berry V, Axford N, Blower S, Taylor RS, Edwards RT, Tobin K, et al. The effectiveness and micro-costing analysis of a universal, school-based, social-emotional learning programme in the UK: a cluster-randomised controlled trial. School Ment Health. 2015;8:238-56. https://doi.org/10.1007/s12310-015-9160-1.

60. Trueman P, Anokye NK. Applying economic evaluation to public health interventions: the case of interventions to promote physical activity. J Public Health (Bangkok). 2012;35:32-9. https://doi. org/10.1093/pubmed/fds050.

61. John S. John Henry effect. Encycl Res Des. 2010.

62. Stewart-Brown SL, Anthony R, Wilson L, Winstanley S, Stallard N, Snooks H, et al. Should randomised controlled trials be the "gold standard" for research on preventive interventions for children? J Child Serv. 2011;6:228-35. https://doi.org/10.1108/17466 661111190929

63. University of Manchester. Pay scale - 51 point scale 2016-17. Manchester: University of Manchester; 2016.

64. Department for Education. School workforce in England: November 2015. London: Department for Education; 2015.

65. National Union of Teachers. NUT GUIDANCE ON THE TEACHERS' PAY STRUCTURE FOR 2014/15. 2014.

66. National Union of Teachers. School teachers' pay: NUT guidance on pay appeals September 2014. London. 2014. 